\title{
Consultant psychiatrists' working patterns: is a progressive approach the key to staff retention?
}

\begin{abstract}
AIMS AND METHOD
The aim of the study was to explore how different styles of working relate to measures of occupational pressure experienced by consultant psychiatrists. A questionnaire was sent to a random sample of 500 consultant psychiatrists enquiring about work patterns, roles and responsibilities; it also contained validated tools, including the 12-item General Health Questionnaire.
\end{abstract}

\author{
RESULTS \\ A total of 185 usable questionnaires \\ were returned; an adjusted response \\ rate of $41 \%$. More 'progressive' styles \\ of working were found to be linked \\ with less occupational pressure on \\ consultant psychiatrists. Three scales \\ were derived: positive workload \\ pattern, clarity of role and perceived \\ support.
}

\author{
CLINICAL IMPLICATIONS \\ Alterations in working style may be \\ helpful in combating occupational \\ stress, and therefore in reducing \\ attrition in the psychiatric workforce. \\ Consultants and their teams should \\ give consideration to reviewing their \\ roles and patterns of working.
}

The shortfall in consultant numbers in the UK is welldocumented. The Royal College of Psychiatrists' census puts the vacancy rate in 2001 at $12 \%$ overall, with regional and sub-specialty peaks far above this (Royal College of Psychiatrists, 2002). Factors that are encouraging older consultants to consider early retirement as well as those affecting senior house officers' career decisions include overt bureaucracy, high workloads and lack of free time (Mears et al, 2002). Although these factors may seem to be fixed and external, different ways of working do exist and can be influential in improving retention. Kennedy \& Griffiths (2001) suggested, on the basis of a qualitative survey undertaken using a 'snowball' method to collect data on patterns of working, that some consultant psychiatrists were already adopting a new role, characterised by effective delegation to other team members, effectively managed referrals, protection of non-clinical time, low numbers of fixed contract sessions and progressive multidisciplinary team working. They also suggested that this new way of working might be associated with lower levels of stress than the older, more traditional way.

As a part of a more comprehensive study of workload and workload patterns among consultant psychiatrists and approved social workers, we investigated both new and traditional patterns of working and how these relate to stress and burn-out among consultant psychiatrists. This project was commissioned by the Department of Health as part of a rolling programme of research to investigate recruitment and retention issues affecting psychiatry.

\section{Method}

A questionnaire was sent to 500 consultant psychiatrists in the UK; selected from a list of practising consultants obtained from the Royal College of Psychiatrists. The selection was randomised using the Statistical Package for the Social Sciences (SPSS version 11.5). Consultants who did not respond were sent two reminder letters, the second enclosing another copy of the questionnaire. The design was informed by three specialty-specific focus groups (the specialties were general adult psychiatry, old age psychiatry, and child and adolescent psychiatry). The form included sections for demographic data, work patterns, roles and responsibilities (including a section derived from the questionnaire compiled by Kennedy \& Griffiths, 2001), with extra items directly taken from the focus group output, job content and work environment. Other sections used validated tools: the Karasek Job Content Questionnaire (JCQ; Karasek et al, 1998), the Maslach Burnout Inventory (MBI; Maslach \& Jackson, 1993) and the 12-item version of the General Health Questionnaire (GHQ; Goldberg, 1992).

The resulting data were analysed using SPSS version 11.5.

\section{Results}

\section{Development of the scales}

A total of 185 questionnaire forms were returned, an adjusted response rate of $41 \%$. Data from the 18 questionnaire items regarding working patterns were subjected to a principal components analysis (PCA) in order to reduce the data into a manageable format for further analyses. The PCA varimax rotation converged in seven iterations, yielding three factors, identified by their factor loadings as follows:

- Positive workload pattern: a high score was indicated by a positive, progressive workload pattern, as suggested by low accumulation of patients from other members of the multidisciplinary team, scope for delegation within the team, little experience of rising personal case-loads, little experience of postgraduate training activities being squeezed out, little experience of struggling to find time to respond to emergencies, little need to defer 
original papers emergencies until the end of the day, stable fixed sessions, and little difficulty in keeping the number of fixed sessions low in order to be able to respond to requests for support from other professionals.

- Clarity of role: a high score was indicated by a low level of ambiguity surrounding the consultant's role, with the consultant taking low numbers of referrals from general practitioners, and feeling low/no levels of isolation and illness, feeling little or no squeezing of their role by other agencies and professionals, feeling little or no conflict between therapeutic engagement and containment, and feeling a high reliance on other team members to manage specific patients.

- Perceived support: a high 'perceived support' score was indicated by reporting a high level of support from the multidisciplinary team (referrals and follow-ups are diverted from the consultant where appropriate), and good access to the Chief Executive of their health care trust. The scales created showed the following values for internal validity.'Positive workload pattern', derived from the scores of 8 of the 18 items, had a Cronbach's $\alpha$ of 0.794 , suggesting a reliably linked set of measures $(\alpha>0.7$ : Pallant, 2001). Cronbach's $\alpha$ for 'clarity of role' derived from the scores of 6 of the 18 items was 0.444 , and for 'perceived support', derived from the scores of the remaining 4 items, $\alpha=0.419$. Although the latter two values were less than 0.7 , it is quite common for scales with few items to have low $\alpha$ values (Pallant, 2001), and the scales can be viewed as internally valid, despite their low scores.

The following relationships with the three roles identified by Kennedy \& Griffiths (2001) are apparent:

- The 'traditional' role can be said to be characterised by a heavy workload (a low score for positive workload pattern), ambiguity of role (low clarity of role score) and lack of perceived support (low score).

\section{Table 1. Relating workload pattern to occupational pressures}

\begin{tabular}{lrrr} 
The higher the consultants' score on the positive workload pattern scale & $r$ & $n$ & $P$ \\
\hline The more delighted (v. terrible) they felt about their current job & 0.491 & 168 & $<0.01$ \\
The lower they scored on the JCQ Psychological Job Demand scale & -0.485 & 181 & $<0.01$ \\
The lower they scored on the MBI Emotional Exhaustion scale & -0.438 & 178 & $<0.01$ \\
The lower their GHQ score & -0.371 & 179 & $<0.01$ \\
The more satisfied ( $v$. disappointed) they felt & -0.356 & 181 & $<0.01$ \\
The higher they scored on the JCQ Social Support scale & 0.353 & 170 & $<0.01$ \\
The higher they scored on the JCQ Decision Latitude scale & 0.335 & 179 & $<0.01$ \\
\hline
\end{tabular}

GHQ, General Health Questionnaire; JCQ, Job Content Questionnaire; MBI, Maslach Burnout Inventory.

\section{Table 2. Relating role clarity to occupational pressures}

\begin{tabular}{llrl} 
The greater the clarity surrounding the consultants' role ... & $r$ & $n$ & $<$ \\
\hline The more delighted ( $v$. terrible) they felt about their current job & 0.443 & 168 & $<0.01$ \\
The more satisfied ( $v$. disappointed) they felt & -0.412 & 181 & $<0.01$ \\
The lower they scored on the MBI Emotional Exhaustion scale & -0.384 & 178 & $<0.01$ \\
The lower they scored on the MBI Depersonalisation scale & -0.37 & 179 & $<0.01$ \\
The higher they scored on the JCQ Social Support scale & 0.333 & 170 & $<0.01$ \\
The higher they scored on the JCQ Decision Latitude scale & 0.311 & 179 & $<0.01$ \\
The lower their GHQ score was & -0.273 & 179 & $<0.01$ \\
The lower they scored on the JCQ Psychological Job Demands scale & -0.225 & 181 & $<0.01$ \\
The higher they scored on the MBI Personal Accomplishment scale & 0.179 & 172 & $<0.05$
\end{tabular}

GHQ, General Health Questionnaire; JCQ, Job Content Questionnaire; MBI, Maslach Burnout Inventory.

\section{Table 3. Relating perceived support to occupational pressures}

The better the consultants' perceived support...

\begin{tabular}{ccc}
$r$ & $n$ & $P$ \\
\hline 0.353 & 168 & $<0.01$ \\
0.322 & 170 & $<0.01$ \\
0.269 & 179 & $<0.01$ \\
-0.213 & 181 & $<0.01$
\end{tabular}

The more delighted ( $v$. terrible) they felt about their current job

The higher they scored on the JCQ Social Support scale

The higher they scored on the JCQ Decision Latitude scale

The more satisfied ( $v$. disappointed) they felt

$-0.213$

$<0.01$

The more satisfied ( $v$. disappointed) they felt 
- The emerging new role (progressive working) is characterised by a positive workload pattern, little ambiguity of role, and high perceived support (high score on all three scales).

- The 'adapted traditional' role does not sit happily with the newly created scales, since it describes a largely symbiotic relationship between two consultants working very closely together. It is difficult to ascertain at what point on the continuum of the three scales this type of consultancy role would fit.

Tables 1, 2 and 3 show (by means of Pearson's correlations) the relationship between the newly-created work scales and job satisfaction, GHQ, MBI and JCQ scores.

The consultants were divided into two groups according to whether their score on the GHQ was low or high, and a one-way analysis of variance was used allowing comparison of the mean scores for each of the three scales between the two groups. Consultants in the low-scoring group had a more positive workload pattern $(F=20.488$, d.f. $=1, P<0.01)$, and felt that less ambiguity surrounded their role $(F=8.896$, d.f. $=1, P<0.01)$. No significant interaction was observed between GHQ score and the perceived support variable.

\section{Discussion}

The results from this survey are clear. Consultant psychiatrists working in a more progressive way, akin to Kennedy \& Griffiths' (2001) 'new' role, appear to suffer less from occupational pressure than do their more traditional colleagues. Through their greater integration within the multidisciplinary team, these consultants have more control over the volume of referrals and the size of their case-load, delegating to and depending upon other members of the team. The 'new' consultant role may well be an important factor in reducing burn-out and stressrelated illness, and in improving the level of job satisfaction; it may help to reduce the attrition of consultants through early retirement.

The response rate to our survey was low, perhaps reducing the impact and generalisability of its findings. The large number of responders and the face validity of the role patterns identified suggests, however, that at the very least these patterns warrant further study. It should also be noted that although it was not possible to provide a casewise match of responders and nonresponders, the data seem to cover a broad range of those working as consultant psychiatrists.

It is clear that developments in patterns of working are potentially important ways of retaining key staff. It is fundamental, however, that consultant roles are not considered in isolation: for any change in the role of health care professionals to be effective (and, more importantly, not counterproductive), its impact upon other team members must be considered and agreed to by the team as a whole. Only by examining the team as a whole, exploring all team members' roles and their contribution to the overall service, identifying the competencies and skill mix of teams and monitoring the effects of role changes, will we be able to plan the greater integration of multidisciplinary teams and perhaps reduce the stresses of working in mental health.

\section{References}

GOLDBERG, D. (1992) General Health Inventory (2nd edn). Palo Alto: Questionnaire (GHQ-12).Windsor: Consulting Psychologists Press. NFER-Nelson.

KARASEK, R., BRISSON, C., KAWAKAMI, N., et al (1998) The job content questionnaire (JCQ): an instrument for internationally comparative assessments of psychological job characteristics Journal of Occupational Health Psychology, 3, 322-355

KENNEDY, P. \& GRIFFITHS, H. (2001) General psychiatrists discovering new roles for a new era ... and removing work stress (editorial). British Journal of Psychiatry, 179, 283-285.

MASLACH, C. \& JACKSON, S. E. (1993) MEARS, A., KENDALL, T., KATONA, C. et al (2002) Career Intentions in Psychiatric Trainees and Consultants (CIPTAC). Report submitted to Department of Health. London: Royal College of Psychiatrists' Research Unit.

PALLANT, J. (2001) SPSS Survival Manual. Milton Keynes: Open University Press.

ROYAL COLLEGE OF PSYCHIATRISTS (2002) Annual Census of Psychiatric Staffing 2001. Occasional Paper OP54. London: Royal College of Psychiatrists. original

papers

*Alex Mears Research Fellow, Royal College of Psychiatrists' Research Unit, 83 Victoria Street, London SW1H OHW (tel: 020 7227 0835; fax: 0207227 0850; e-mail: alex.mears@virgin.net), Sarah Pajak ResearchWorker, Tim Kendall Deputy Director, Royal College of Psychiatrists' Research Unit, Cornelius Katona Dean, Royal College of Psychiatrists, Jibby Medina Research Assistant, Royal College of Psychiatrists' Research Unit, Peter Huxley Professor of Social Work, Institute of Psychiatry, Sherrill Evans Research Coordinator, Claire Gately ResearchWorker, Institute of Psychiatry, London 